Kalem Eğitim ve İnsan Bilimleri Dergisi 2019, 9(1), 1-25, doi: 10.23863/kalem.2019.118

Makale Gönderim Tarihi:06.06.2017 Makale Kabûl Tarihi:29.01.2018

\title{
Zihinsel Yetersizliği olan Öğrencilere Fen Konularının Öğretiminde Doğrudan Öğretim Yöntemi ile Şematik Düzenleyiciyle Öğretim Yönteminin Karşılaştırılması
}

\author{
Arş. Gör. Derya ÇIKILI SOYLU \\ Maltepe Üniversitesi, Eğitim Fakültesi, Özel Eğitim Bölümü, İstanbul/Türkiye \\ deryacikili@maltepe.edu.tr, ORCID: 0000-0002-6806-2449 \\ Dr. Öğr. Üyesi Deniz DAĞSEVEN EMECEN \\ Maltepe Üniversitesi, Eğitim Fakültesi, Özel Eğitim Bölümü, İstanbul/Türkiye \\ denizemece@maltepe.edu.tr, ORCID: 0000-0001-6663-3933 \\ Doç. Dr. Ahmet YIKMIŞ \\ Abant İzzet Baysal Üniversitesi, Eğitim Fakültesi, Özel Eğitim Bölümü, Bolu / Türkiye, \\ yikmis_a@ibu.edu.tr, ORCID: 0000-0002-1143-1207
}

\section{$\ddot{\mathbf{O} z}$}

$\mathrm{Bu}$ araştırmanın genel amacı; hafif derecede zihinsel yetersizliği olan öğrencilere Fen konularının (İskelet ve Solunum Sistemi) kazandırılmasında ve kalıcılığında doğrudan öğretim yöntemi ile şematik düzenleyici ile hazırlanan öğretim programlarının etkililiğinin belirlenmesidir. Araştırma deneklerini, 2015-2016 öğretim yılında 'Şeyh Şamil Ortaokulu’ özel eğitim sınıfında yer alan öğrenciler arasından belirlenen bir

* Sorumlu Yazar. Tel: 05355587822

(C) 2019 Kalem Eğitim ve Sağlık Hizmetleri Vakfı. Bütün Hakları Saklıdır. ISSN: 2146-5606 
kız, bir erkek öğrenci oluşturmuştur. Araştırmada tek denekli araştırma modellerinden, uyarlamalı dönüşümlü uygulamalar modeli kullanılmıştır. Her iki denek; İskelet Sistemi ve Solunum Sistemi konularının doğrudan ve şematik düzenleyiciler ile hazırlanan öğretim planının öğretimi ve sunumu sonunda, iskelet ve solunum sistemi konularını kazanmışlardır. Aynı zamanda her iki denek için; İskelet Sistemi ve Solunum Sistemi konularının öğretiminde şematik düzenleyiciler ile doğrudan öğretim yönteminin etkililik açısından farklılaşmadığı izlenimi edinilmektedir. Doğrudan öğretim ve şematik düzenleyiciler ile yapılan öğretimden, 15 ve 25 gün sonra, öğrenilen İskelet ve Solunum Sistemi konularının kalıcılığını devam ettirmesi açısından farkl1lık göstermediği izlenimi edinilmektedir.

Anahtar Kelimeler: Doğrudan öğretim yöntemi; Şematik düzenleyiciler; Fen öğretimi; Zihinsel yetersizliği olan çocuklar; Öğretim planı.

\title{
Comparison of Direct Teaching Method and Graphic Organizers Method on Teaching Science to Children with Intellectual Disability
}

\begin{abstract}
The general aim of the research is to determine the effectiveness of the curriculum prepared with the direct method and schematic organizers in teaching science subjects (Skeletal and Respiratory System) to the students with intellectual disabilities. Research subjects are one girl and one boy, who are students in special education classroom of Şeyh Şamil Secondary School in 2015-2016 academic year. Interchangeably adaptive applications model, which is one of the single subject experimental designs, is used in the research. Both subjects have learned skeletal and respiratory topics at the end of the prepared teaching plans designed to teach skeletal system and respiratory system with direct and schematic teaching. Also for both subjects, it is thought that schematic and direct teaching methods did not differ significantly in terms of the effectiveness on teaching skeletal and respiratory system topics. After 15 and 25 days, it is thought schematic and direct teaching methods did not differ significantly in terms of long lasting on teaching skeletal and respiratory system topics.
\end{abstract}

Key Words: Direct teaching method; Graphic organizers; Science teaching; Children with intellectual disabilities; Teaching plan.

\section{Extended Summary}

Science and technology education play a key role in the future of societies, as scientific information is increasing exponentially, technological in- 
novations are advancing at a great speed, and the effects of science and technology are clearly seen in all areas of our lives. Considering these developments in our country, together with linguistics, mathematics and social studies courses; science is one of the four main subject areas. Science and Technology Course Teaching Program presents the basis of the lessons, which are to be presented at a higher level throughout primary school classes, with a specific curriculum structure by taking into account individual differences (MEB, 2005). Although the difference between the learning styles and levels of the students is indicated; sufficient importance is not given to science course in the curriculum for individuals with mental disabilities. As these students began to spend most of their school days as integration students in general education classes, the shortcomings in science teaching curricula began to be taken into consideration and many difficulties were identified (Polloway, Serna, Patton and Bailey, 2013).

In order to transfer scientific process skills to the students in the best way via science teaching, teachers need to choose the best method. When it is considered that the chosen method and subject should be chosen according to the student's level; Concept diagrams, problem solving model, activity centered approach, demonstration, direct teaching method and teaching with schematic organizers are the most used methods (Çepni and Çil, 2013).

One of the teaching methods that can be used in courses that are well developed and planned, and emphasize clearly defined and predicted teaching objectives such as Mathematics, Life Science, Social Studies, Science and Technology, is the direct teaching method (Dağseven, 2001). The core of the direct teaching method is to teach in small steps, to practice the student after each step, to guide the students in the first practice, and to ensure that all students have a high level of successful practice (Schug, Tarver and Western, 2001).

Science curriculum contains many concepts, phenomena, scientific generalizations and principles. A structured view of the information can be used to bring the different science content to the students. The basic rationale of the schematic organizers is to provide information in a meaningful and consistent whole, and to visualize the organizational structure of information (Mercell and Snell, 1977). 


\section{Purpose}

According to the literature review; there are very few studies on the effectiveness of the methods used in science teaching for students with intellectual disabilities. This research differs from the work done in the literature in terms of two features. Firstly; when the literature was examined, no studies were found on the teaching science subjects directly and with the schematic organizers. It is considered that the teaching processes prepared for this study will lead to teachers working on the field about how to teach these subjects with direct teaching method and schematic organizers. Secondly; there was no study examining the effectiveness of direct and schematic teaching in the teaching and persistence of science subjects. It has been decided which method is more effective in the teaching of these subjects and it will be determined which method is more advantageous in maintaining the permanence of the subjects.

Due to the reasons mentioned above; the general aim of the research is to determine the effectiveness of the curriculum prepared with the direct method and schematic organizers in teaching science subjects (Skeletal and Respiratory System) to the students with intellectual disabilities.

\section{Method}

The research design is "adaptive rotation applications model" from the single subject experimental designs. Independent variables of the study; teaching applications of Skeletal System and Respiratory System units taught by direct teaching method and schematic organizers. The level of learning of the skeletal and respiratory systems of the students is the dependent variable.

The study group of the study; is 2 students with mild intellectual disabilities, who continue to special education class in the 2015-2016 academic year, at Şeyh Şamil Secondary School in İstanbul. For the determination of the working group; firstly the teachers were interviewed; students, who can $\mathrm{read} /$ write, who understands what he is reading, who can give short answers to the questions directed to him, who can solve the four-choice multiple choice test, who knows the parts of the body and sense organs; but with no knowledge of skeletal and respiratory systems have been selected. Teacher interview forms were applied to the both students and was determined that they have no knowledge about the Skeletal and Respiratory System. 


\section{Results}

In both of the students, the data inclination path and direction showing the level of learning the science subjects increased according to starting the data inclination path and direction at the end of the teaching done with the teaching approaches. As a result, it has been reached the impression that students gained the science subjects by both methods, and it has also been reached the impression that the teaching of the subjects with the direct teaching and schematic organizers is of similar effectiveness in the acquisition of science subjects.

Skeletal and Respiratory System concepts that students have acquired at the end of instruction with direct teaching and schematic organizers appear to have continued in the same place 15 and 25 days after the end of instruction. Therefore, the impression is that teaching with direct teaching method and schematic organizers do not differ in terms of maintaining the persistence of the learned Science subjects (Skeleton and Respiratory System).

\section{Discussion}

In a result of the research, it has been determined that teaching with direct teaching method enables both students to learn Science subjects (Skeletal System and Respiratory System). At the same time, this result, which is achieved through research, is also consistent with previous research (Çelik, 2007; Dağseven, 2001; Dağseven-Emecen, 2008; Ekergil, 2000; GüzelÖzmen, 1998; Kahyaoğlu, 2010; Kırcaali-İftar, Birkan ve Uysal, 1998; Varol, 1992) that examines the effectiveness of the direct teaching method.

When results of this study are examined, it has been determined that teaching with schematic organizers enables both students to learn Science subjects (Skeletal System and Respiratory System). At the same time, this result, which is achieved through research, is also consistent with previous research (Davis, 1994; Gardill ve Jitendra, 1999; Grünke, Wilbert and Stegmann, 2013; Güzel-Özmen, 2011; Horton, Lovitt ve Bergerud, 2001; Vayiç, 2008) that examines the effectiveness of the schematic organizers.

However, with the schematic organizers the information presented in teaching was integrated and input organization was provided. Besides, the information was sequenced and the relations between them was visualized. For these reasons, the data obtained at the end of the instruction prepared with the schematic organizers is higher than the direct teaching percentage. 
Within the scope of this research, maintaining permanence are also observed after 15 and 25 days of teaching The Skeletal System and Respiratory System with direct teaching and schematic organizers and there was no difference between them in terms of permanence, but in his work Vajic (2008) observed that Teaching with Schematic Organizers is more effective than Direct Teaching in maintaining student achievements 15 days after teaching.

\section{Conclusion}

In the light of research findings, for researchers and educators; it can be suggested to teachers and those working on the field that these two approaches can be used in the teaching of science subjects, as the teaching practices with direct teaching and schematic organizers are not so different from each other in terms of effectiveness and retention.

The skeletal and respiratory system measurement tools prepared in this study, plans and teaching materials prepared for these subjects with direct teaching and schematic organizers can be used by teachers and field workers. In further research; differentiating effectiveness of direct teaching and schematic organizers in teaching of different Science and Technology subjects and the acquisition and persistence of these subjects can be studied. At the same time, it can be studied that whether group teaching in the teaching of science subjects with direct teaching and teaching with the schematic organizers leads to the realization of the goals.

\section{Giriş}

Günümüz çağında bilimsel bilgiler katlanarak artmakta ve teknolojik yenilikler büyük bir hızla ilerlemekte ve bu ilerlemeler yaşamımızın her alanında belirgin bir şekilde görülmektedir. Bu gelişmelerin temelinde öğrencilere verilen fen ve teknoloji eğitiminin ve okuryazarlığının anahtar bir rol oynadığg görülmektedir. Bu nedenle, bireylerin ve toplumların kendilerine güçlü bir gelecek oluşturabilmeleri için her vatandaşın fen ve teknoloji okuryazarı olarak yetişmesi gerekmektedir (Çepni ve Çil, 2013; MEB, 2005). Fen ve teknoloji yazarlı̆̆ı; tüm çocuklara düşünce sanatının öğretilmesini, deneyimlere dayanan fen kavramlarının zihinde geliştirilmesini, sebep-sonuç ilişkisinin nasıl irdelenip analiz edilebileceğini ve kullanılacak yöntemlerin nasıl öğretilmesi gerektiğini hedef almaktadır (Tobin, 1986).

Ülkemizde eğitim müfredatı Türkçe, matematik, sosyal bilgiler derslerinin yanı sıra fen ve teknoloji dersinin yer aldığ 4 temel konu alanından oluşmaktadır. Fen ve teknoloji dersi öğretim programı; ilkokul sınıfları boyunca 
daha ileri düzeyde sunulacak derslerin temelini belirli bir müfredat yapısı ile aktarır ve bireysel farklılıkları göz önünde bulundurarak, bütün öğrencilerin fen ve teknoloji okuryazarı olarak yetişmesini temel alır (MEB, 2005). Öğrencilerin öğrenme stilleri ve düzeyleri arasındaki fark belirtilmiş olsa da; fen, zihinsel yetersizliği olan öğrenciler için kullanılan müfredatta daha az öncelikli yer almaktadır. Bu öğrenciler okul günlerinin büyük bir kısmını genel eğitim sınıfları ile beraber kaynaştırma öğrencisi olarak geçirmeye başlayınca fen müfredatında görülen eksiklikler göz önüne gelmeye başlamış ve birçok problem ortaya çıkmıştır (Polloway, Serna, Patton ve Bailey, 2013).

Yetersizliği olan öğrencilere fen ve teknoloji dersindeki kavramların kazandırılmasında yaşanan zorluklar; okuma sorunları, dikkat bozukluğu veya davranış problemleri çatısı altında toplanmaktadır. Bu problemlere sahip olan öğrencilerin ölçme performansında ve kavramsal olarak karmaşık olan içerikleri, yönergeleri ve etkinlikleri anlamada zorluklar yaşadıkları gözlenmiştir. Yaşadıkları bu zorluklar güdülenme eksikliği, grup çalışmalarına uygun biçimde katılamama ve öğrenilmiş çaresizlikler olarak ortaya çıkmıştır. Bunun sonucunda da derse katılımlar azalmıştır. Etkin bir şekilde not tutamadıkları, kaynak kullanmadıkları ve materyalleri analiz etmede problem yaşadıklarından dolayı çalışmaları bitiremedikleri ve sınavlara hazırlanmada problem yaşadıkları gözlenmiştir (Polloway ve ark., 2013). Bu problemlere çözüm olarak fen öğretimi yapılırken öğretmenlerin temel ilke, kavram ve becerilerin öğretimi yerine, belirli bilimsel tutum ve değerleri geliştirmeye odaklanarak ve bir bilim adamı gibi dersleri yürüterek; fen programını çekici bir hale getirmeleri gerektiği vurgulanmıştır (Patton, Bailey ve Cronin, 1994). Alanyazın incelendiğinde ilgi çeken bir fen programı sunulduğu zaman çoğu öğrenci, uyarılmasına rağmen, bazı öğrencilerin dikkatini çekmediği ve başka stratejilerin kullanılması gerektiği gözlenmiştir. Bu durumda öğretmenler, özel gereksinimli öğrencilerin performans düzeylerini dikkate alarak, özellikle bilgi edinme alanlarında fen becerilerinin farkında olmaları gerektiği belirlenmiştir (Bringham, Scruggs ve Mastropieri, 1992).

IDEA bu konuda temel olarak şunu belirtmiştir; özel gereksinimli olan öğrencilerin erken dönemde fen ile ilgilenmeleri sağlanmalı, bu ilgi yaşam boyu devam ettirilerek kavram ve beceriler uzun vadede anlamlı k1lınmalıdır (Polloway ve ark., 2013). Bu ilginin devam ettirilebilmesi için; fen eğitiminde daha az konuya daha çok zaman ayrılması ve ünitelerin güncel hayata yakın konulardan seçilmesi gerektiği, aynı zamanda kavram gelişimini hedefleyen 
bilgi temelli öğrenme ve değerlendirme şekline yönelinmesi gerektiği belirtilmiştir (Gurganus, Janas ve Schmitt, 1995).

Yukarıda belirtilen zorluklar göz önüne alındığında fen öğretimi yapılırken farklı içerikteki konular için farklı sunumlar yapılması gerekmektedir. Birçok sınıf öğretmeni ve özel eğitim öğretmeni; yetersizliği olan öğrencilere fen bilgisi konularını öğretmek için yeterince hazırlanamadıklarından dolayı, s1k s1k kelime odaklı, içerik yönelimli, ders anlatma ve gösteri gibi öğretmen merkezli sunumlar kullandıklarını belirtmişlerdir (Güzel-Özmen, 2012). Fen öğretimi ile bilimsel süreç becerililerinin en iyi şekilde öğrencilere aktarılabilmesi için; öğretmenlerin ders anlatırken en iyi yöntemi seçmeleri gerekmektedir. Seçilen yöntem ve konunun öğrenci düzeyine göre seçilmesi gerektiği düşünüldügü zaman; kavram diyagramları, problem çözme modeli, aktivite merkezli yaklaşım, demonstrasyon, doğrudan öğretim yöntemi ve şematik düzenleyicilerle öğretim en çok kullanılan yöntemlerdir (Çepni ve Çil, 2013).

Matematik, hayat bilgisi, sosyal bilgiler ve fen ve teknoloji gibi iyi geliştirilmiş ve planlanmış, net tanımlanmış ve öngörülmüş öğretim hedeflerini içeren derslerde kullanılabilecek öğretim yöntemlerinden biri doğrudan öğretim yöntemidir (Dağseven, 2001). Doğrudan öğretim yönteminin temelinde; küçük adımlarla öğretme, her adımdan sonra öğrenciye alıştırma yaptırma, ilk alıştırmada öğrencileri yönlendirme ve bütün öğrencilerin alıştırmalarını başarılı bir şekilde bitirmeleri bulunmaktadır (Schug, Tarver ve Western, 2001). Doğrudan öğretim yöntemi, öğretimin organize edilmesine yardımc1 olur. Böylece belirli bir beceri düzeyine sahip öğrencilere daha fazla bağımsız çalışma imkânı sağlarken, belirli beceri düzeyi altında kalan öğrenciler daha fazla öğretmen ile beraber yapılandırılmış bir ortamda çalışma imkânı sunar. Yani bu yöntem ile öğretim organize edilerek, öğrenciler yeni öğretilen konuları kazanır, akılda tutar ve genellerler (Carnine, Silbert ve Kameenui, 1990; Dağseven-Emecen, 2008; Güzel-Özmen, 2012).

Doğrudan öğretim yönteminin temelinde bütün çocukların öğrenebileceği ve öğretimin planlı, eksiksiz ve hatasız öğrenme deneyimlerini sağlayacak şekilde planlanması yatmaktadır. Böylece hedef öğretimin tasarlanmasında ve yürütülmesinde verimlilik en üst düzeye çıkarılarak öğrenme hızlandırılmış olunur (Watkins, 1995). Doğrudan öğretim, ülkemizde zihinsel engelli öğrencilere matematik öğretimi (Bayram, 2006; Dağseven, 2001; Eliçin, Dağseven-Emecen ve Yıkmış, 2013; Kahyaoğlu, 2010; Karakoç, 2002; 
Kroesbergen ve Van Luit, 2005; Polat, 1996; Şahbaz, 2005; Varol, 1992), okuduğunu anlama öğretiminde (Güzel-Özmen, 1998) kullanılmış ve etkili olduğu bulunmuştur. Yapılan alanyazın taramasında hafif derecede yetersizliği olan öğrencilerde fen ve teknoloji dersine ilişkin kavramların öğretiminde doğrudan öğretim yönteminin etkili bir yöntem olduğu İlik (2009) tarafindan belirlenmiştir.

Fen müfredatı çok sayıda kavramı, olguyu, bilimsel genellemeyi ve ilkeyi içermektedir. Farklı özellikteki fen konularını öğrencilere kazandırmak için bilginin yapılandırılmış görünümü kullanılabilir. Öğrenmeyi yapılandırarak öğrencinin öğrenmesine destek sunma amacı ile geliştirilen yöntemlerden biri de şematik düzenleyicilerdir. Şematik düzenleyicilerin temel mantığı; bilgilerin anlamlı ve tutarlı bir bütün şekilde sunulmasını sağlamak ve bilgilerin organizasyonel yapısını görselleştirmektir (Mercell ve Snell, 1977) düzenleyiciler Ausubel'in bilişsel teorisine dayalı olarak; bireyin kazanılmış olan bilgisinin onun bilişsel yapısını oluşturduğunu ve önceki öğrenmeler ile bir araya gelerek yeni öğrenmeler ile birleşeceğini savunmuştur (Güzel-Özmen, 2011).

Zihinsel yetersizliği olan öğrencilerin yapılandırılmamış bilgiyi kategorilere yerleştirmede problemleri olduğu saptanmıştır (Güzel-Özmen, 2011). Yapılan araştırmalar incelendiğinde, şematik düzenleyicilerle öğretimin hem normal gelişim gösteren öğrencilerde hem de öğrenme güçlüğü olan öğrencilerde bilgi veren metinleri anlamada etkili ve verimli olduğu tespit edilmiştir (Coşkun, Gür ve Aykutlu, 2014; Dönmez, Yazıcı ve Sabancı, 2007; Grıffın, Simons ve Kameenu1, 1991; Grıffın, Malonee ve Kameenu1, 1995; Güzel-Özmen, 2011; Horton, Lovitt ve Bergereud, 1990). Şematik düzenleyicilerle öğretim, Sosyal Bilgiler ve Fen Bilgisi gibi derslerde özellikle öğrenme güçlügüne sahip öğrencilerin okuma problemlerini çözerek metinleri anlamalarına yardımcı olmak, akademik başarılarını arttırmak için, alternatif yöntem olarak kullanılmış ve etkili olduğu belirlenmiştir (Darch ve Carnine, 1986; Darch, Carnine ve Kameeniui, 1986; Duman ve Çiftci-Tekinarslan; 2007; Güzel-Özmen, 2011, 2012; Horton, Lovitt ve Bergeud, 1990; Hudson, Lignugaris-Kraft ve Miller, 1993; Sazak-Pınar ve Merdan, 2013).

Alanyazında fen konularının öğretiminde doğrudan öğretim ve şematik düzenleyicileri içeren çalışmalardan; Bay, Staver, Bryan ve Hale (1992), Doğrudan Öğretim Yöntemi ve Keşfederek Öğretim Yönteminin, hafif derecede yetersizliği olan ve yetersizliği olmayan öğrencilerin fen başarıları üzerinde 
etkisini araştıran çalışma dikkati çekmektedir. Bu araştırmada deneme modellerinden "Ön test-Son test Kontrol Gruplu Model” kullanılmıştır. Araştırmanın deneklerini, öğrenme güçlüğü ve duygusal bozukluğu olan öğrenciler ile onların sınıf arkadaşları içinden seçilen, Chicago kentinde bir devlet okuluna devam eden 138 öğrenci oluşturmuştur. Araştırmanın sonucunda, iki grupta bulunan öğrencilerin eşit olarak sunulan konuyu öğrendikleri bulunmuşstur. Bununla birlikte Keşfederek Öğrenme Yönteminin uygulandığ grubun, Doğrudan Öğretim Yönteminin uygulandığı gruba göre, son test uygulandıktan iki hafta sonra uygulanan izleme testi sonuçlarına göre daha iyi performans gösterdiği gözlenmiştir. Genelleme ölçümünde, Keşfederek Öğrenme Yöntemi uygulanan öğrenme güçlüğü olan öğrencilerin, Doğrudan Öğretim Yöntemine oranla daha iyi performans sergiledikleri gözlemlenmiştir.

Ülkemizde yapılan çalışmalar incelendiğinde, Vayiç (2008) zihinsel yetersizliği olan öğrencilere hayat bilgisi öğretiminde doğrudan öğretim yöntemi ile şematik düzenleyici ile verilen öğretimi karşılaştırmıştır. Çalışma grubuna alınan bu öğrencilerin dördü hazırlık sınıfına, üçü birinci sınıfa, beşi ise ikinci sınıfa giden altısı kız, altısı erkek olarak seçmiştir. Araştırmada deneme modellerinden "Ön test-Son test Kontrol Gruplu Araştırma Modeli” kullanılmıştır. Araştırma sonucunda Hayat Bilgisi kavramlarının öğretiminde Şematik Düzenleyiciyle Öğretimin zihinsel yetersizlikten etkilenmiş öğrencilerin başarı düzeylerinde erişi puanları açısından Doğrudan Öğretimden daha etkili olduğu, son test puanları açısından farklılaşmanın olmadığ ifade edilmiştir. Ayrıca öğretimden 15 gün sonra öğrencilerin kazanımlarını sürdürmede Şematik Düzenleyiciyle Öğretimin, Doğrudan Öğretime göre daha etkili olduğunu belirlemiştir.

Sazak-Pınar ve Merdan (2013) otizmli öğrencilere fen bilgisi konularının öğretiminde grafik düzenleyiciler kullanılarak sabit bekleme süreli öğretim yönteminin etkililiğini araştırmışlardır. Araştırmanın deneklerini 10-11 yaşlarında bir kız iki erkek öğrenci oluşturmuştur. Bu denekler için önkoşul becerisi olarak; görsel ve işitsel uyaranlara beş dakika süre ile dikkatini yöneltebilme, sıra alma becerisine sahip olma, sözel yönergeleri takip edebilme ve üç ve dört kelimeden oluşan cümleler kurarak ifade edici dil becerilerine sahip olmaları şeklinde belirlenmişlerdir. Araştırma modeli olarak tek denekli araştırma modellerinden denekler arası yoklama evreli çoklu yoklama modelini kullanmışlardır. Araştırmada öğrencilere 'sindirim olayının nasıl gerçekleştiği’ öğretilmiştir. Çalışmanın sonunda; sabit bekleme süreli öğretim yöntemiyle sunulan grafik düzenleyicilerin kullanımının otizmli öğrencilere fen 
bilgisi kavramlarının öğretiminde etkili olduğunu, deneklerin bu kavramlara ilişkin elde ettikleri kazanımları öğretim sona erdikten bir, iki ve üç hafta sonra devam ettirdikleri ve öğretilen kavramlara ilişkin bilgileri de farklı ortama genelleyebildikleri gözlenmiştir.

Alanyazın incelendiğinde, zihinsel yetersizliği olan öğrencilere fen öğretiminde kullanılan yöntemlerin etkililiği ile ilgili çok az çalışmaya rastlanmaktadır. Bu araştırma, alanyazında yapılan çalışmalardan iki özelliği bakımından farklılık göstermektedir. İlk olarak alanyazın incelendiği zaman belirlenen fen konularının doğrudan ve şematik düzenleyiciler ile öğretimi konusunda herhangi bir çalışmaya rastlanmamıştır. Bu çalışma için hazırlanan öğ retim süreçlerinin, konuların doğrudan öğretim yöntemi ve şematik düzenleyiciler ile nasıl öğretileceği konusunda alanda çalışan öğretmenlere yol göstereceği düşünülmektedir. İkinci olarak fen konularının öğretiminde ve kal1cılığında doğrudan ve şematik düzenleyici ile öğretimin etkililiğini inceleyen bir çalışmaya rastlanmamıştır. Bu konuların öğretiminde hangi yöntemin daha etkili olduğuna karar verilmiş olunup, konuların kalıcılığını devam ettirmede hangi yöntemin daha avantajlı olduğu belirlenmiş olacaktır.

Yukarıda bahsedilen gerekçelerden dolayı; araştırmanın genel amacı hafif derecede zihinsel yetersizlikten etkilenmiş olan öğrencilere fen konularının (İskelet ve Solunum Sistemi) kazandırılmasında ve kalıcılığında doğrudan ve şematik düzenleyici ile hazırlanan öğretim programının etkililiğininim belirlenmesidir. Böylece, ilerleyen araştırmalara ve alanda çalışan öğretmenlere yol göstereceği düşünülmektedir.

\section{Yöntem}

Araştırmanın deseni, tek denekli deneysel desenlerden "uyarlamalı dönüşümlü uygulamalar modeli”dir. İki ya da daha fazla bağımsız değişkenin, iki ya da daha fazla geriye dönüşü olmayan bağımlı değişken üzerinde etkisini incelemek amaciyla kullanılan bir modeldir. Alanyazın incelendiği zaman uyarlamalı dönüşümlü uygulamalar modelinin; işlevsel, gelişimsel ve akademik becerilerin öğretimindeki gibi geriye dönüşü olmayan davranışların öğretilmesinde ve bağımsız değişkenlerin hızla dönüştürülmesini gerektiren uygulamalarda kullanılmasının uygun olduğu belirtilmiştir (Halcombe ve Wolery, 1994; Tekin, 2000; Wolery, Gast ve Hammound, 2010).

Uyarlamalı dönüşümlü uygulamalar modelinde deneysel kontrol, bir bağımsız değişkenin ilişkili olduğu bağımlı değişkendeki değişikliğin, diğer bağımsız değişkenle ilişkili olan bağımlı değişkendeki değişiklikten daha hızlı 
olması ile sağlanır (Halcombe ve Wolery, 1994; Sindelar, Rosenberg ve Wilson, 1985; Tekin, 2000). Araştırmanın bağımsız değişkenlerini; İskelet Sistemi ile Solunum Sistemi ünitelerinin doğrudan öğretim yöntemi ve şematik düzenleyiciler ile yapılan öğretim uygulamaları, bağımlı değişken ise; öğrencilerin iskelet ve solunum sistemi konularını öğrenme düzeyleridir.

\section{Çalışma Grubu}

Araştırmanın çalışma grubunu; 2015-2016 öğretim yılında İstanbul İlinde Şeyh Şamil Ortaokulu'nun özel eğitim sınıfına devam eden, hafif derecede zihinsel yetersizliği olan iki öğrenci oluşturmuştur. Çalışma grubunun belirlenmesi için; öncelikle öğretmenler ile görüşme yapılmış; okuma/yazma bilen, okuduğunu anlayan, kendisine yönlendirilen sorulara kısa cevaplar verebilen, dört seçenekli çoktan seçmeli testi çözebilen, vücudun bölümlerini ve duyu organlarını bilen; fakat iskelet ve solunum sistemleri hakkında bilgi sahibi olmayan dört öğrenci seçilmiştir.

Ediz, hafif derecede zihinsel yetersizlik tanısı almış, 13 yaşında, bir erkek öğrencidir. Vücudun bölümleri ve duyu organları resimli kartlar ile göstertildiği zaman isimlerini söylemekte; kendi vücudunda gösterebilmektedir.

Masal, hafif derecede zihinsel yetersizlik tanısı almış, 12 yaşında, bir k1z öğrencidir. Vücudun bölümleri ve duyu organları resimli kartlar ile göstertildiği zaman isimlerini söylemekte; kendi vücudunda gösterebilmektedir. Her iki öğrenciye de, öğretmen görüşme formları uygulanmış ve İskelet ve Solunum Sistemi ile ilgili bilgilere sahip olmadıkları belirlenmiştir.

\section{Veri Toplama Araçları}

Öğrencilerin konuların öğretiminde kullanılacak olan yöntemlerin gerektirdiği önkoşullara sahip olup olmadıklarını belirlemek amacıyla önkoşul ölçü araçları geliştirilmiştir. İskelet ve Solunum Sistemi ünitesinin öğretimi için, gerekli olan önkoşul formu için 2 bildirimden oluşan ölçüt bağımlı ölçü aracı hazırlanmıştır. Bu önkoşul araçlar öğrencilere üçer kez uygulanmış, yönerge verildikten sonra 3-4 saniye cevap vermeleri için beklenmiştir. Öğrencilerin doğru ve yanlış cevaplarına tepkisiz kalınmıştır. Öğrenciler cevap vermediyse 1-2 saniye beklenmiş ve soru tekrarlanmıştır. Öğrencilerin doğru cevap verdiyse doğru cevap olarak (+), öğrenci cevap vermediyse veya yanlış cevap verdiyse yanlış tepki olarak (-) veri kayıt çizelgesine işaretlenmiştir ve bir sonraki soruya geçilmiştir. Öğrencilerin çalışma davranışları 'Aferin! Beni çok güzel dinliyorsun!' diyerek ödüllendirilmiştir. 
Araştırmada öğrencilerin öğretim öncesinde ve sonrasında iskelet sistemi ve solunum sistemi konularında düzeyini belirlemek için "İskelet Sistemi Ölçü Aracı" ve "Solunum Sistemi Ölçü Aracı" ve her iki öğretim yaklaşımıyla yapılan öğretim sırasında öğrencilerin ilerlemelerini kaydetmek amaciyla veri kayıt formları hazırlanmıştır. İskelet Sistemi Ölçü Aracının amacı, öğrencinin İskelet Sistemi konusunda neler bilip neleri bilmediğini yani düzeyini ölçmektir. Ölçü aracında iskelet sistemi konusunu kapsayacak şekilde toplam 10 bildirim; her bildirim için de 4 soru hazırlanmıştır. Solunum Sistemi Ölçü Aracının amacı ise öğrencinin solunum sistemi konusunda neler bilip neleri bilmediğini yani düzeyini ölçmektir. Ölçü aracında solunum sistemi konusunu kapsayacak şekilde toplam 8 tane bildirim; her bildirim için de sorular hazırlanmıştır. 1., 2., 3., 7. ve 8. bildirimler için 4 soru; 4. ve 5. bildirimler için 3 soru; 6 . bildirim için ise 2 soru hazırlanmıştır. Deneklerin tepkide bulunmaması ya da yanlış tepkide bulunması durumunda (-), doğru tepkide bulunması durumunda ise kayıt çizelgesinin üzerine $(+)$ konulmuştur.

Geliştirilen ölçü araçları sorularının anlaşılabilirliğini belirlemek amacıyla; özel eğitim sınıfına devam eden ve önkoşul özellikleri karşılayan 2 öğrenciye uygulanmıştır. Öğrencilerin sorulara doğru tepkiler vermesi sebebi ile soruların anlaşılır olduğu düşünülmüş ve uygulanmasına karar verilmiştir. Ayrıca, fen ve teknoloji ve özel eğitim öğretmenlerinden ölçü aracı ile ilgili görüş alınmış ve uygulanabilir olduğuna karar verilmiştir.

\section{Öğretim Ünitelerindeki Öğretim Planlarının Sunulması}

Öğretim planlarının sunulması doğrudan öğretim yöntemi ve şematik düzenleyicilerle öğretim olmak üzere 2 başlıkta toplanmıştır.

\section{Doğrudan Öğretim Yöntemi ile İskelet ve Solunum Sistemi Öğre- tim Planları}

Öğretim süreci başında öğrenciye oturum boyunca yapacakları ve oturum sonunda kazanacakları açıklanmıştır. Öğretim sürecinde kullanılacak araçlar öğrenciye gösterilmiş ve bir süre incelemesine izin verilmiştir. Doğrudan öğretim yöntemine göre ders planları, materyaller, öğretime hazırlık, model olma, rehberli uygulama ve bağımsız uygulama bölümlerinden oluşmuştur. Model olma aşamasında; uygulamacı konuda yer alan bilgileri sözel olarak sıralamış ve bir kaç kez tekrar etmiştir. Öğrenciye konuda yer alan resimli kartlar sırasıyla gösterilmiş ve resimli kartlar hakkında konuşulmuştur. Ardından öğrenciye tek tek resimli kartlar gösterilerek; beraber konu tekrarı sağlanmıştır. Öğrenci doğru tepki verince betimlenerek pekiştirilmiş, eksik ya 
da yanlış tepki verdiğinde ise dönüt ve düzeltmeler verilerek doğru tepki vermesi sağlanmıştır. Rehberli uygulamalar aşamasında, ipucunun verildiği aşamada, öğrenciye model olma aşamasında öğretilenler sorulmuştur. Öğrenciye zarf içinde resimli kartlar dağıtılmış, önüne dizmesi söylenmiş ve karışık olarak dizilmiş resimli kartlar arasından uygulamacının sorduğu resimli kartı göstermesi istenmiştir. Ardından resimli kartı sözel bilgi haline getirmesi istenmiştir. Bu aşamada öğrenciye her aşama için ana yönergeler verilmiş ve doğru resimli kartı bulması sağlanmıştır. İpucunun geri çekildiği aşamada; resimli kartlar toplanılmış ve yeni zarflar dağıtılmıştır. Öğrenciden karışık olarak dizilmiş resimli kartlar arasından uygulamacının sorduğu resmi seçip söylemeleri istenmiştir. Bu aşamada sadece öğrencilere hatırlatıcı yönergeler verilmiştir. Öğrenci doğru tepki verdiğinde betimlenerek pekiştirilmiş eksik ya da yanlış tepki verdiğinde dönüt ve düzeltmeler verilerek doğru tepki vermesi sağlanmıştır. Resimli kartlar öğrencide toplanmıştır. Bağımsız uygulamalar aşamasında; öğretim sonlarında, öğrenciye hazırlanan çalışma kâğıtları verilmiştir. Öğrenciden soruları okuması ve doğru cevapları gösterilen şekilde işaretlemesi istenmiştir. Doğu cevaplar pekiştirilmiş, yanlış cevaplarda ise ipucu ve dönütlerle doğru cevap buldurulmuştur. Oturumun sonunda, öğrencilere öğretim boyunca öğrenilenler tekrar edilmiş ve bir sonraki oturumda yapılacak olan çalışmalar söylenmiştir. Uygun çalışma davranışları betimlenerek pekiştirilmiş ve kazanılan ödül hatırlatılarak çalışma sonlandırılmıştır.

\section{Şematik Düzenleyiciler ile İskelet ve Solunum Sistemi Öğretim Planları}

Öğretim süreci başında öğrenciye oturum boyunca yapacakları ve oturum sonunda kazanacakları açıklanmıştır. Öğretim sürecinde kullanılacak araçlar öğrenciye gösterilmiş ve bir süre incelemesine izin verilmiştir. Öncelikle öğrenciye çalışmanın adı, çalışma boyunca uyulması gereken kurallar ve çalışmanın sonunda kazanacağı ödül açıklanmıştır. Kullanılacak öğretim materyalleri tanıtılmıştır.

Öğrenciye konu ile ilgili soru sorulmuş ve cevapları tepki verilmeden kayıt edilmiştir. Sonrasında uygulamacı şemasını önüne koyarak ne yapacağını açıklamış ardından da, öğrenci şemasını da öğrenciye göstermiş ve ne şekilde doldurulacağı açıklanmıştır. Konu ile ilgili sözel bilgi, fişler arasından bulunup şemaya yapıştırılmıştır. Şema öğrenci ile tekrar ettirilmiş, bilgiler sözel hale getirilmiştir. Ardından konuda yer alan resimli kartlar gösterilerek, şemaya yapıştırılmıştır ve şema toplu olarak tekrar edilmiştir. Ardından öğrenciye şeması, zarf içerisinde yer alan fişleri ve resimli kartları verilmiştir. 
Öğrenciye yönergeler verilerek kartları şemasına yapıştırması istenmiş, doğru olarak kartları yapıştırır ise betimlenerek pekiştirilmiş, yanlış yapıştırırsa dönüt ve düzeltmelerle doğru olan kartı yapıştırması sağlanmıştır. Öğrenciden şemasını özetlemesi istenmiştir. Öğrenci anlatırken ihtiyaç duyduğu yerlerde sorular sorularak anlatması için ipucu verilmiştir. Öğrencinin uygun çalışma davranışları betimlenerek pekiştirilmiş ve ödül verilerek çalışma sonlandırılmiştır.

İskelet sistemimiz konusu üç oturumda öğretilmiştir. Birinci oturumda, kemiklerin tanımı, kemiklerin görevi, çeşitleri ve vücutta bulunana yerlerin öğretilmesi amaçlanmıştır. Bu konunun öğretimi için 'kemiklerimiz' araç setini kullanılmıştır. İkinci oturumda, kasların tanımına, kasların görevine, çeşitlerine ve vücutta bulunduğu yerlerin öğretilmesi amaçlanmıştır. Bu konunun öğretimi için 'kaslarımız' araç setini kullanılmıştır. Üçüncü oturumda ise, iskelet ve kas sisteminin sağlı̆̆ına ilişkin hangi hareketlerin yapılması ve hangi besinlerin alınması gerektiğinin öğretilmesi amaçlanmıştır. Bu konunun öğretimi için 'iskelet sistemi sağlığımız' araç seti kullanılmıştır.

Solunum sistemimiz konusu üç oturumda öğretilmiştir. Birinci oturumda, solunum sisteminin görevi, organları ve organların görevinin öğretilmesi amaçlanmıştır. Bu konunun öğretimi için 'solunum sistemimiz 'araç seti kullanılmıştır. İkinci oturumda, soluk alıp-verme konusunun öğretilmesi amaçlanmıştır. Bu konunun öğretimi için 'soluk alıp-verme araç seti kullanılmıştır. Üçüncü oturumda ise, solunum sisteminin sağllğına ilişkin nelerin yapılması ve hangi besinlerin alınması gerektiğinin öğretilmesi amaçlanmıştır. Bu konunun öğretimi için 'solunum sistemimizin sağlığı' araç seti kullanılmiştır.

\section{Deney Süreci}

Uygulama boyunca her bir denek için başlama düzeyi oturumlarına, uygulama evresine, öğretim sonu bağımsızlık yoklamalarına ve kalıcılık oturumlarına yer verilmiştir. Uygulama süreci toplam 11 gün sürmüştür.

Başlama düzeyi verileri, her bir denek için 3 ayrı günde 3 ayrı oturumda toplanmıştır. Her oturum, deneklerin sınıftan alınması ile başlamış ve çalışmanın sonunda, deneğin çalışma ortamından çıkarılıp sınıfa tekrar bırakılması ile sonuçlanmıştır. 
Araştırmanın uygulama evresinde, bir günde her bir ünite için yirmi beşer dakikalık birer oturum düzenlenmiştir. İki denek için bir günde ikişer öğretim oturumu olmak üzere, toplam dört öğretim oturumu gerçekleştirilmiştir ve uygulama evresi üç gün sürmüştür. Her bir öğretim oturumu arasında 5 dakika ara verilmiştir.

Öğretim oturumlarında öğrenciler ile hangi konunun hangi yöntem ile çalış1lacağ random yöntemi ile belirlenmiştir. Uygulama verilerinin toplanmasına, İskelet Sistemi ünitesi Ediz ile doğrudan öğretim yaklaşımı ile çalış1larak başlanmıştır. Aynı gün içerisinde Ediz ile Solunum Sistemi konusu şematik düzenleyiciler ile çalışılmıştır. Yine aynı gün içinde, Masal ile İskelet Sistemi konusu şematik düzenleyiciler ile çalış1lırken, Solunum Sistemi doğrudan öğretim yöntemi ile çalışılmıştır. Sonuçta aynı gün içerisinde, her öğrenciye, bir konu bir yöntemle, diğer konu diğer yöntemle olmak üzere iki yöntem dönüşümlü olarak uygulanmıştır.

Uygulama evresi, araştırmacı tarafından gerçekleştirilmiştir. Her bir öğretim oturumu, öğrencilerin sınıftan alınması ile başlamış ve çalışmanın sonunda öğrencilerin sınıftan çıkarılıp, sınıfa tekrar yönlendirilmesi ile sonuçlanmıştır.

\section{Öğretim Sonu Bağımsızlık ve Kalıcılık Verilerinin Toplanması}

İskelet Sistemi ve Solunum sistemi konularının doğrudan öğretim ve şematik düzenleyiciler ile öğretim uygulamaları tamamlandıktan sonra, deneklerin öğretim sonu düzeyleri belirlenmiştir. Deneklerin öğretim sonu düzeylerinin belirlenmesinde, İskelet Sistemi ve Solunum Sistemi ölçü araçları 3 ayrı günde 3 ayrı oturumda uygulanmıştır. Her bir öğretim oturumu, öğrencilerin sınıftan alınması ile başlamış ve çalışmanın sonunda öğrencilerin sınıftan çıkarılıp, sınıfa tekrar yönlendirilmesi ile sonuçlanmıştır. Ayrıca 3 oturumda yoklama evreleri alınmış ve sorulara verdikleri cevapların kararlılığı belirlenmiştir. Deneklerin, iskelet ve solunum sistemi konularını öğrendikten belli bir süre sonra kalıcılığını devam ettirip ettirmediğini değerlendirmek için, öğretim oturumlarından 15 ve 25 gün sonra kararlılık verisi toplanmıştır. $\mathrm{Bu}$ amaçla deneklere, iskelet ve solunum sistemi ölçü araçları bire bir olarak birer kez daha uygulanmıştır.

\section{Verilerin Analizi}

Tek denekli deneysel desenlerden uyarlamalı dönüşümlü uygulamalar modelinin kullanıldığ bu araştırmada, veriler grafik olarak analiz edilmiş ve grafikler niceliksel olarak yorumlanmıştır. Grafiksel analiz tekniklerinden de 
çizgisel grafik kullanılmıştır. Hazırlanan grafikte yatay eksene her iki öğretim yaklaşımına ait başlama düzeyi, öğretim sırası, kararlılık ve kalıcılık oturumları yerleştirilmiştir, dikey eksene ise her bir oturuma karşılık gelen doğru tepki yüzdesi, düşey eksen üzerinde 0-100 arasında eşit aralıklarla gösterilmiştir. Bir öğretim yaklaşımına ait davranış oluşum yüzdesini gösteren eğrinin eğim yolu ve yönü, diğer öğretim yaklaşımına ait eğriye göre, farklılık göstermiyor ve birbirleriyle binişiyorsa, iki öğretim yaklaşımının etkililik bakımından birbirinden farklı olmadığı sonucuna varılmıştır. Eğer, eğrilerin eğim yolu ve yönü binişmiyor ve bir öğretim yaklaşımına ait eğrinin yönü, diğer öğretim yaklaşımına ait eğriden daha yukarıya doğruysa, o öğretim yaklaşımının diğerine göre daha etkili olduğu izlenimi edinilmiştir.

\section{Uygulama Güvenirliği Verilerinin Analizi}

$\mathrm{Bu}$ araştırmada, uygulama güvenirliği için yüzde hesaplamaları yapılmıştır. Uygulama güvenirliği katsayısı, gözlenen uygulamacı davranışının, planlanan uygulamacı davranışına bölünerek yüzdesinin alınması ile hesaplanmıştır. Gözlemcilerin her biri, Doğrudan öğretim ve Şematik Düzenleyiciyle öğretim gruplarının birer öğretim oturumunu, yani oturumların \%20'sini izlemiştir. Uygulama güvenirliği gözlemcinin izlediği videoları değerlendirmesi ile [(Gözlenen uygulamacı davranış1/planlanan uygulamacı davranış1)]x100 formülü kullanılarak hesaplanmıştır (Tekin-İftar ve Kırcaali-İftar, 2004). Araştırma oturumlarında uygulamacının yerine getirdiği davranışlar sayılarak, veri toplama aracında yer alan tüm davranışların sayısına bölünmüş ve yüzle çarpılmıştır. Uygulama güvenirliği analizinin sonuçları iskelet ve solunum sistemi konularının öğretimi için iki denekte de \%100 çıkmıştır. Araştırmanın uygulamacı güvenirliğinin yüksek çıkması uygulayıcının iskelet ve solunum sistemi konularının öğretiminde iki öğrencide de planlandığg şekilde uyguladığı sonucunu çıkarmaktadır.

\section{Gözlemciler Arası Güvenirlilik Verilerinin Analizi}

Gözlemciler arası güvenirlik genellikle, gözlemciler arası görüş birliğinin gözlemciler arası görüş birliği ve gözlemciler arası görüş ayrılığı toplamına bölünüp yüzdesinin alınması ile hesaplanır (Görüş birliği/Görüş ayr11ığ1+Görüş ayrılığıx100) (Kırcaali-İftar ve Kırcaali-Tekin, 2004). Görüş birliği, her iki gözlemcinin de bir soruya öğrencinin verdiği tepkiyi aynı olarak kaydetmesidir. Görüş ayrılığı ise, her iki gözlemcinin de deneğin verdiği yanıtı farklı değerlendirmeleridir. Güvenirlik hesaplamalarında $\% 80$ gözlemciler arası güvenirlik katsayısı kabul edilebilir, $\% 90$ ve üstü ideal güvenirlik 
katsayısı olarak kabul edilmektedir (Kırcaali-İftar ve Tekin, 1997). Araştırmada; gözlemci tarafından kaydedilen veriler, araştırmacının kayıtlarıyla karş1laştırılmıştır. (Görüş birliği/Görüş ayrılığı + Görüş birliğix100) formülü kullanılarak gözlemciler arası güvenirlik hesaplanmıştır. Öğrencilerin iskelet ve solunum sistemi konularının öğretiminde, gözlemciler arası güvenirlik verileri; birinci öğrenci için güvenirlik ortalamas1 \%98, ikinci öğrenci için güvenirlik ortalaması $\% 92$ olarak hesaplanmıştır. Güvenirlik ortalaması, birden fazla oturumda toplanan katsayıların toplamının katsayıların oturum sayısına bölünmesiyle elde edilmiştir (Kırcaali-İftar ve Tekin, 1997).

\section{Bulgular}

\section{Doğrudan Öğretim ve Şematik Düzenleyiciler ile Yapılan Öğreti- min Etkililiklerine ve Kalıcılığına İlişkin Bulgular ve Yorumlar}

Araştırmanın birinci amacında, İskelet ve Solunum Sistemi fen konularının öğretiminde, doğrudan öğretim ve şematik düzenleyiciler ile yapılan öğretimden hangisinin daha etkili olduğunu belirlemek amaçlanmıştır. Bu amaca yönelik olarak her bir öğrencinin doğrudan öğretim ve şematik düzenleyiciler ile yapılan öğretim sırasındaki bulguları Grafik 1 ve Grafik 2'de verilmiştir.

Grafik 1 incelendiğinde, birinci öğrenci doğrudan öğretim yaklaşımıyla yapılan öğretim sırasında veri eğim yönünün giderek arttığı, iskelet sistemi ile ilgili \%87.5 ölçüt düzeyine ulaştığı ve yoklama verisinde de veri eğim yönünün aynı düzeyde kaldığı yani konuyu \%87.5 düzeyinde kazandığı görülmektedir. Ayrıca birinci öğrenci şematik düzenleyicilerle yapılan öğretim sırasında veri eğim yönünün giderek arttığı, solunum sistemi ile ilgili \%100 ölçüt düzeyine ulaştığı ve yoklama verisinde de veri eğim yönünün aynı düzeyde kaldığı yani konuyu öğrencinin konudaki kavramları kazandığı gözlemlenmiştir.

Grafik 2 incelendiğinde ikinci öğrenci; doğrudan öğretim yaklaşımıyla yapılan öğretim sırasında veri eğim yönünün giderek arttığı, iskelet sistemi ile ilgili \%100 ölçüt düzeyine ulaştığ1 ve yoklama verisinde de veri eğim yönünün aynı düzeyde kaldığı yani konuyu öğrencinin konudaki kavramları kazandığı gözlemlenmiştir. Ayrıca ikinci denek doğrudan öğretim yaklaşımıyla yap1lan öğretim sırasında veri eğim yönünün giderek arttı̆̆ 1 , iskelet sistemi ile ilgili \%87.5 ölçüt düzeyine ulaştığı ve yoklama verisinde de veri eğim yönünün aynı düzeyde kaldığı yani konuyu \%87.5 düzeyinde kazandığı görülmektedir. 


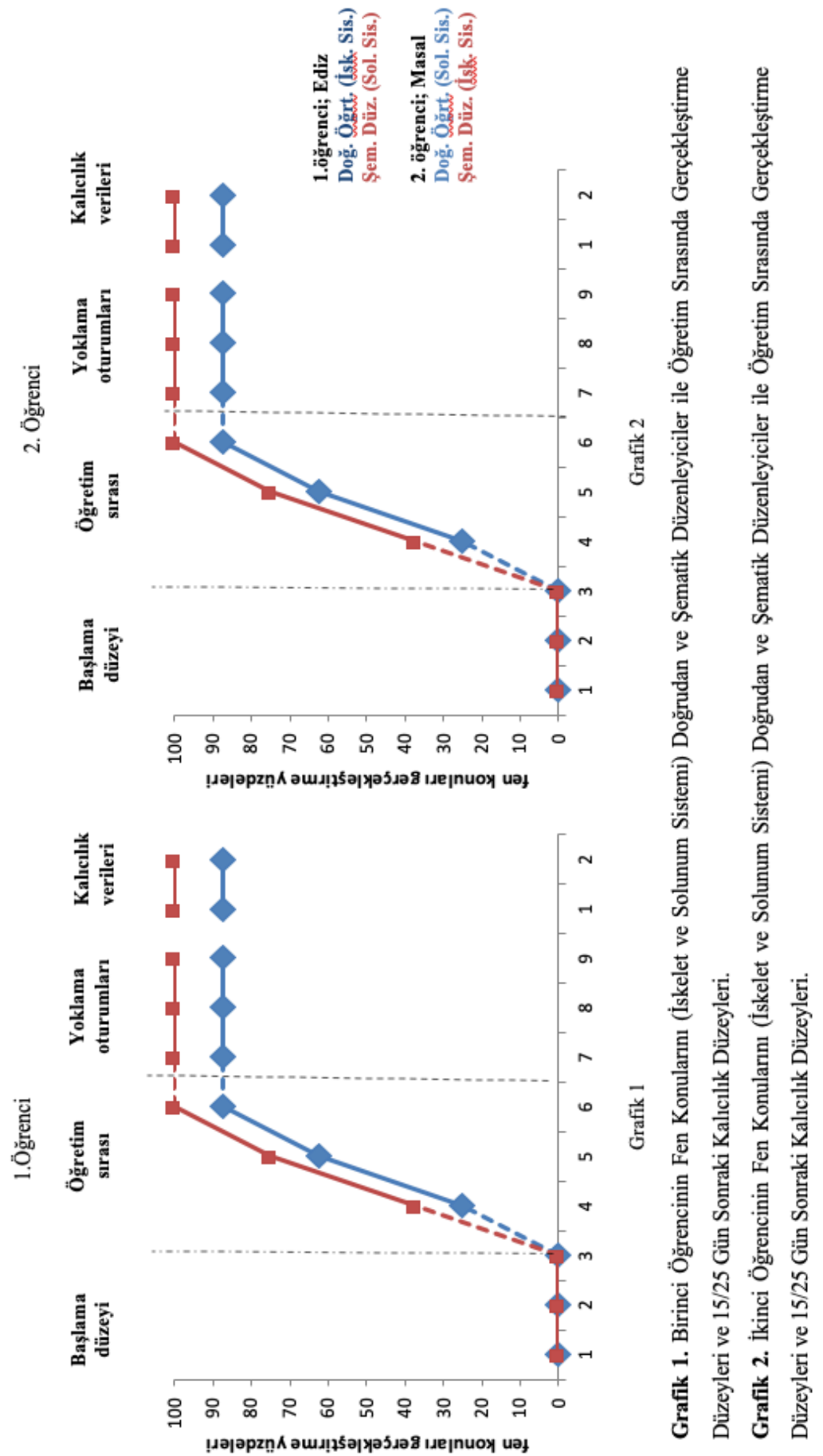


Her iki öğrenci için de, doğrudan öğretim ve şematik düzenleyici ile yapılan öğretim sonucunda fen konularını kazanma düzeyini gösteren veri eğim yolu ve yönü, başlama düzeyi veri eğim yolu ve yönüne göre artış göstermiştir. Sonuç olarak öğrencilerin fen konularının her iki yöntem ile de kazandıkları izlenimi edinilmiş, ayrıca fen konularının kazanımında doğrudan öğretim ve şematik düzenleyiciler ile yapılan öğretimin benzer etkililikte olduğu izlenimi edinilmiştir.

Grafik 1 ve Grafik 2'de görüldüğü gibi, deneklerin doğrudan öğretim ve şematik düzenleyiciler ile yapılan öğretim sonunda kazandıkları İskelet ve Solunum Sistemi kavramları, ögretim bittikten 15 ve 25 gün sonra da aynı oranda sürdürdükleri görülmektedir. Dolayısıyla, doğrudan öğretim ve şematik düzenleyiciler ile yapılan öğretimin, öğrenilen fen konularının (İskelet ve Solunum Sistemi) kalıcılığını devam ettirme açısından farklılık göstermediği izlenimi edinilmektedir.

\section{Tartışma ve Sonuç}

Araştırmanın sonucunda, doğrudan öğretim yöntemi ile yapılan öğretimin her iki öğrencide de, fen konularını (İskelet Sistemi ve Solunum Sistemi) öğrenmelerini sağladığı belirlenmiştir. Nitekim İlik (2008) fen ve teknoloji dersine ilişkin kavramların öğretilmesinde doğrudan öğretim yöntemi ile yapılan öğretimlerin etkili olduğunu belirlemiştir. Aynı zamanda araştırma ile ulaşılan bu sonuç, doğrudan öğretim yönteminin etkililiğini inceleyen daha önce yapılan araştırmalarla da (Çelik, 2007; Dağseven, 2001; DağsevenEmecen, 2008; Ekergil, 2000; Güzel-Özmen, 1998; Kahyaoğlu, 2010; Kırcaali-İftar, Birkan ve Uysal,1998; Varol, 1992) tutarlılık göstermektedir.

Araştırmada sonucunda, şematik düzenleyiciler ile yapılan öğretimin her iki öğrencide de, fen konularını (İskelet Sistemi ve Solunum Sistemi) öğrenmelerine yol açtı̆̆ bulunmuştur. Nitekim Dönmez, Yazıcı ve Sabanc1, (2007) Şematik Düzenleyicilerle Öğretim ile Geleneksel Öğretim Yöntemini Sosyal Bilgiler dersinde karşılaştırmışlardır. Öğrencilerin akademik bilgiyi elde etmelerinde Şematik Düzenleyici ile Öğretimin etkili olduğunu bulmuşlardır. Aynı zamanda araştırma da ile ulaşılan bu sonuç, şematik düzenleyicilerin etkililiğini inceleyen daha önceki araştırmalarla da (Davıs, 1994; Gardill ve Jitendra, 1999; Grünke, Wilbert ve Stegmann, 2013; Güzel-Özmen, 2011; Horton, Lovitt ve Bergerud, 2001; Vayiç, 2008) tutarl11ı göstermektedir. 
Araştırmanın ilk amacında; doğrudan öğretim ve şematik düzenleyiciler ile yapılan öğretimden hangisinin, öğrencilerin fen konularını (İskelet Sistemi ve Solunum Sistemi) kazanmalarında daha etkili olduğu araştırılmıştır. Her iki denek için de şematik düzenleyiciler ile doğrudan öğretim yönteminin benzer etkililikte olduğu izlenimi edinilmiştir. Her iki yöntemde de bilgiler küçük basamaklar halinde sunulmuştur. Ancak şematik düzenleyiciyle öğretimde sunulan bilgiler bütünleştirilerek girdi organizasyonu sağlanmış, bilgiler sıralı hale getirilerek, aralarındaki ilişkileri görselleştirilmiştir. Bu nedenlerle şematik düzenleyiciler ile hazırlanan öğretim sonunda elde edilen veriler doğrudan öğretim yüzdesine göre daha yüksek olduğu izlenimi edinilmiştir. Nitekim Vayiç (2008) hayat bilgisi dersindeki konuların öğretiminde doğrudan öğretim yöntemi ile şematik düzenleyiciler ile yapılan öğretimlerin etkililiklerini karşılaştırmış ve şematik düzenleyiciler ile yapılan öğretimlerin daha etkili olduğunu belirtmiştir. Bay, Staver, Bryan ve Hale'in (1992) araştırmasında da benzer sonuç elde edilmiştir. Fen Bilgisi öğretiminde doğrudan öğretim yöntemi ile keşfederek öğretim yöntemi karşılaştırılmış, keşfederek öğrenmenin daha etkili olduğu gözlemlenmiştir.

Aynı zamanda araştırmanın son amacında; fen konularını (İskelet Sistemi ve Solunum Sistemi) doğrudan ve şematik düzenleyiciler ile yapılan öğretimlerinden 15 ve 25 gün sonra kalıc1lıklarını devam ettirmelerine bakılmıştır, kalıcılık bakımından aralarında bir farklılaşma olmadığı gözlenmiştir. Fakat Vayiç (2008) yaptığ çalışmasında; öğretimden 15 gün sonra öğrencilerin kazanımlarını sürdürmede Şematik Düzenleyiciyle Öğretim, Doğrudan Öğretime göre daha etkili olduğunu gözlemlemiştir.

Araştırma bulguları 1şı̆̆ında uygulamacı ve eğitimcilere yönelik olarak; doğrudan öğretim ve şematik düzenleyiciler ile yapılan öğretim uygulamaları etkililikleri ve kalıcılıkları açısından birbirinden çok fazla farklı bulunmadığı için, öğretmenlere ve alanda çalışan kişilere, fen konularının öğretiminde kullanılmak üzere bu iki yaklaşımı da kullanmaları önerilebilir. Bu araştırmada hazırlanan iskelet ve solunum sistemi ölçü araçları, planları ve bu konular için hazırlanan doğrudan öğretim ve şematik düzenleyiciler ile sunulan öğretim materyalleri, öğretmenlerce ve alanda çalışan kişilerce kullanılabilir. İlerleyen araştırmalarda; farklı fen ve teknoloji konularının öğretiminde doğrudan ve şematik düzenleyici ile öğretimin, bu konuların kazanılmasına ve kalıcıllğına yol açıp açmadığına ve farklılaşan etkililiklerine bakılabilir. Aynı zamanda fen konularının öğretiminde, doğrudan öğretim ve şematik düzenleyici ile 
grup ile öğretim yapıldığında, amaçların gerçekleşmesine yol açıp açmadığına bak1labilir.

\section{Kaynakça}

Bay, M., Staver, J. R., Bryan, T. ve Hale, J. B. (1992). Science instruction for the mildly handicapped: Direct instruction versus discovery teaching. Journal of Research in Science Teaching, 6(29), 555-570.

Bayram, H. (2006). Az gören ögrencilere uyarlanmış doğrudan öğretim yaklaşımı kullanılarak kendini gözlemleme yoluyla sözlü problem çözme öğretiminin etkililiği. Yayınlanmamış yüksek lisans tezi, Gazi Üniversitesi Eğitim Bilimleri Enstitüsü.

Bringham F., Scruggs T. ve Mastropieri M. (1992). Teacher ethusiasm in learning disabilities calssrom: effects on learning and behaviour. Learning Disabilities Reseach and Practice, 7, 68-73.

Carninne D., Silbert J. ve Kameenui E. (1990). Direct instruction reading. NJ: Merill/Pearson.

Çelik, S. (2007). Zihinsel yetersizlik gösteren çocuklara kavram öğretiminde doğrudan öğretim ve eşzamanl ipucuyla öğretimin etkililik ve verimliliklerin karşılaştırılması. Yayınlanmamış yüksek lisans tezi, Anadolu Üniversitesi Eğitim Bilimleri Enstitüsü.

Çepni, S. ve Çil, E. (2013). Fen ve teknoloji programı ilköğretim el kitabı 1. ve 2. kademe ögretmen el kitabl. Ankara: Pegem Akademi.

Coşkun, İ., Gür, T. ve Aykutlu, H. (2014). Hafif düzey zihin engelli bireylerin okuduğunu anlama düzeyinin belirlenmesi ve yorumlanması amaciyla metin sonrası çizilen resimlerin incelenmesi. Uluslararası Avrasya Sosyal Bilimler Dergisi, 5(14), 17-42.

Dağseven, D. (2001). Zihinsel engelli ögrrencilere, temel toplama ve saat okuma becerilerinin kazandirllmasi, sürekliliği ve genellenebilirliğinde, doğrudan ve basamaklandırılmış öğretim yaklaşımlarına göre hazırlanan ögretim materyallerinin farklılaşan etkililiği. Yayınlanmamış yüksek lisans tezi, Gazi Üniversitesi Eğitim Bilimleri Enstitüsü.

Dağseven-Emecen, D. (2008). Zihinsel yetersizlikten etkilenmiş öğrencilere sosyal becerilerin kazandırılmasında doğrudan ögretim ve bilişsel süreç yaklaşımları ile yapılan ögretimin etkililiklerinin ve verimliliklerinin karşılaştırllması. Yayınlamamış doktora tezi, Gazi Üniversitesi Eğitim Bilimleri Enstitüsü.

Darch, C. ve Carnine, D. (1986). Teaching content area material to learning disabled students. Exceptional Children, 3(53), 240-246.

Darch, C., Carnine, D. ve Kameenui, E. J. (1986). The role of graphic organizers and social structure in content area instruction. Journal of Reading Behavior, 18(4), 275-294.

Davis, Z. T. (1994). Effects of prereading story mapping on elementary readers' comprehension. Journal of Educational Research, 87(6), 353-360.

Dönmez, C., Yazıcı, K. ve Sabancı, O. (2007). Sosyal bilgiler derslerinde grafik düzenleyicilerin kullanımının öğrencilerin akademik bilgiyi elde etmelerine etkisi. Türk Eğitim Bilimleri Dergisi, 5(3), 437-459. 
Duman N. ve Çifci-Tekinarslan, İ. (2007). Hikâye haritası yönteminin zihinsel engelli öğrencilerin okuduğunu anlama becerileri üzerindeki etkisinin belirlenmesi. Ankara Üniversitesi Ĕ̌itim Bilimleri Fakültesi Özel Ĕ̆itim Dergisi, 8(1), 33-35.

Ekergil, G. (2000). Zihin engelli çocuklara zıtlık kavramlarını ögretmede doğal dille uygulanan doğrudan ögretim yönteminin etkililiği. Yayınlanmamış yüksek lisans tezi, Eskişehir Anadolu Üniversitesi Eğitim Bilimleri Enstitüsü.

Eliçin, Ö., Dağseven-Emecen, D. ve Yıkmış, A. (2013). Zihinsel engelli çocuklara doğrudan öğretim yöntemiyle temel toplama işlemlerinin öğretiminde nokta belirleme tekniği kullanılarak yapılan öğretimin etkililiği. M. ̈̈. Atatürk Ĕ̆itim Fakültesi Eğitim Bilimleri Dergisi, 37(37), 118-136.

Gardill, M. ve Jitendra, A. (1999). Advanced story map instruction: effects on the reading comprehension of students with learning disabilities. The Journal of Special Education, 33(1), 2-17.

Griffin, C. C., Malone, L. D. ve Kameenui, E. J. (1995). Effects of graphic organizer instruction on fifth-grade students. The Journal of Educational Research, 89(2), 98-107.

Griffin, C., Simmons, D. C. ve Kammenui, E. J. (1991). Investigating the effectiveness of graphic organizer instruction on the comprehension and recall of science content by students with learning disabilities. Journal of Reading, Writing \& Learning Disabilities International, 7(4), 355-376.

Grünke, M., Wilbert, J. ve Stegemann, K. C. (2013). Analyzing the effects of story mapping on the reading comprehension of children with low intellectual abilities. Learning Disabilities: A Contemporary Journal, 11(2), 51-64.

Gurganas S., Janas M. ve Schmitt L. (1995). Science instruction: what special edcucation teacher need to know and what sole they nees to play. Teaching Excepional Children, 27(4), 7-9.

Güzel-Özmen, R. (2012). Zihinsel engellilerde ögretmenlik uygulaması. Ankara: Pegem Yayıncilik.

Güzel-Özmen, R. (2011). Zihinsel yetersizliği olan öğrencilerin bilgi veren metinlerdeki bilgileri hatırlamalarında şematik düzenleyicilerin iki farklı sunum şeklinin karşılaştırılması. Kuram ve Uygulamada Eğitim Bilimleri, 11(2), 773-793.

Güzel-Özmen, R. (1999). Öykü yapısı ve öykü yapısının okuduğunu anlama öğretiminde kullanılması. Bilig, 11, 105-117.

Güzel-Özmen, R. (1998). Alt özel sinıflardaki ögrencilerin sesli okudukları öyküyü anlama becerilerini kazanmalarında doğrudan öğretim yöntemiyle sunulan bireyselleştirilmiş okuduğunu anlama materyalinin etkililiği. Yayınlanmamış doktora tezi, Gazi Üniversitesi Eğitim Bilimleri Enstitüsü.

Halcombe, A. ve Wolery, M. (1994). Comparative single - subject research: description of designs and discussion of problems. Topics in Early Childhood Special Education, 14(1),119-145.

Horton, S., Lovitt, T. ve Bergerud, D. (2001). The effectiveness of graphic organizers for three classification of secondary students in content area classes. Journal of Learning Disabilities, 23(1), 12-29.

Hudson, P., Lignugaris-Kraft, B. ve Miller, T. (1993). Using content enhancements to improve the performance of adolescents with learning disabilities in content classes. Learning Disabilities Research \& Practice, 8(2), 106-126. 
İlik, Ş. Ş. (2009). Hafif düzeyde öğrenme güçlüğ̈̈ne sahip öğrencilerde doğrudan ögretim yönteminin fen ve teknoloji dersine ilişkin kavramların ögretiminde etkililiğinin değerlendirilmesi, Selçuk Üniversitesi Eğitim Bilimleri Enstitüsü.

Kahyaoğlu, F. (2010). Zihin engelli bireylere ikişerli ve üçerli atlayarak sayma becerisinin ögretiminde doğrudan ögretim yönteminin etkililiği. Yayınlanmamış yüksek lisans tezi, Abant İzzet Baysal Üniversitesi Sosyal Bilimler Enstitüsü.

Kırcaali-İftar, G., Birkan, B. ve Uysal, A. (1998). Comparing the effects of structural and natural language use during direct instruction with children with mental retardation. Education and Training in Mental Retardation and Developmental Disabilities, 33(4), 375-385.

Kroesbergen, E. H. ve Van Luit, J. E. H. (2003). Mathematics interventions for children with special educational needs. Remedial and Special Education, 24(2), 97-114.

MEB. (2005). Illkögretimde fen ve teknoloji dersi ögretim programı. Ankara: Milli Eğitim Basımevi.

MEB. (2005). İş okulu eğitim programı. Ankara: Milli Eğitim Basımevi.

Mercer, C. D. ve Snell, M. E. (1977). Learning theory research in mental retardation. implications for teaching. Ohio: A Bell \& Howell Company.

Polloway E., Serna L., Patton J. ve Bailey J. (2013). Strategies for teaching learners with special needs. NJ: Pearson.

Sazak-Pınar E. ve Merdan F. (2013). Otizmli öğrencilere fen bilgisi kavramlarının öğretiminde sabit bekleme süreli öğretim yöntemiyle sunulan grafik düzenleyicilerin etkililiği. Ahi Evran Üniversitesi Kırşehir Eğitim Fakültesi Dergisi, 1, 111-131.

Sazak-Pınar E. (2014). Özel gereksinimi olan öğrenciler için öğretim stratejileri. Ş. Yücesoy-Özkan, (Ed.), Özel gereksinimi olan ögrenciler için ögrretim stratejileri (10. baskı) içinde (241-263). Ankara: Nobel Akademik Yayıncılık.

Sindelar, P. T., Rosenberg, M. S. ve Wilson, R. J. (1985). An adapted alternating treatments design for instructional research. Education and Treatment of Children, 8(1), 67-76.

Schug M. C., Tarver, S. G. ve Western R. D. (2001). Direct instruction and the teaching of early reading. Policy Reseacrh Institute, 14(2), 5-21.

Şahbaz, Ü. (2005). Zihin engelli ögrencilere çarpım tablosunun ögretiminde sabit bekleme süreli ögretimin hata düzeltmesiz ve hata düzeltmeli uygulamalarının karşılaştırması. Yayınlanmamış doktora tezi, Anadolu Üniversitesi Eğitim Bilimleri Enstitüsü.

Tekin, E. (2000). Karşılaştırmal1-tek denekli araştırma modelleri. Özel Ĕgitim Dergisi, 2, 1-12.

Tekin-İftar, E. ve Kırcaali-İftar, G. (2004). Özel eğitimde yanlışsız ögretim yöntemleri. Ankara: Nobel Yayın Dağıtım.

Tobin, K. (1986). Student task: involvement and achievement in proces-oriented science activities. Science Education, 70(1), 61-72.

Watkins, C. (1995). Follow through: why didn't we? www.darkwing.uregon.edu.tr

Wolery, M., Gast, D. L. ve Hammond, D. L. (2010). Comparative intervention designs. D. L. Gast, (Ed.), Single subject research methodology in behavioral sciences, 181-202. New York: Routledge Publish. 
Varol, N. (1992). Zihinsel engelli çocuklara kırmızı, sarı, büyük, daire, üçgen, uzun, bir tane, iki tane, kalın kavramlarını kazandırmada açık anlatım yöntemiyle sunulan bireyselleştirilmiş kavram ögretim materyalinin etkililiği. Yayınlanmamış doktora tezi, Anadolu Üniversitesi Eğitim Bilimleri Enstitüsü.

Vayiç, Ş. (2008). Zihinsel yetersizlikten etkilenmiş öğrencilere hayat bilgisi ögretiminde doğrudan ögretim yöntemi ve şematik düzenleyiciyle ögretimin karşllaştırılması. Yayınlanmamış yüksek lisans tezi, Gazi Üniversitesi Eğitim Bilimleri Enstitüsü. 